\section{The ABCs of women's}

\section{anatomy}

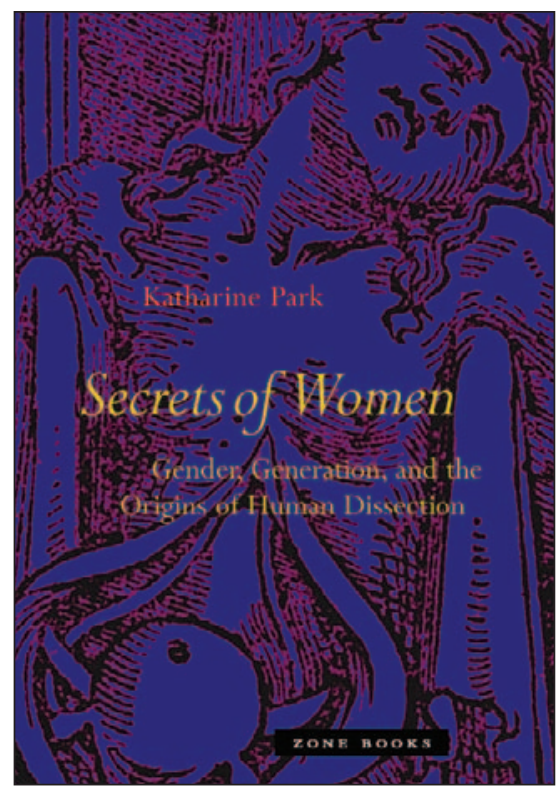

Secrets of Women: Gender, Generation, and the Origins of Human Dissection Katharine Park

Zone Books; 2006

419 pp \$36.95 ISBN: 978-1-890951-67-2

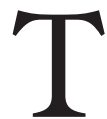
his year, my Io-year-old daughter received "the talk" at school. What I could gather from her report was that it focused on the male and female anatomy, and it was icky in the extreme.

"Did you learn anything?" I asked hopefully.

"Not really," she said. "You already taught me all that stuff when I was 7."

This, then, is the modern reality: school-aged children who have been taught not only about their reproductive organs, but about the kidney, liver and digestive system by the time they reach fifth grade. It is now taken for granted that from an early age, we should be acquainted with how our bodies are made and function. Like super-beings with $\mathrm{x}$-ray vision, we can stare at ourselves in $g$ the mirror and see the pulsing, rolling, churning action of our organs beneath the skin. With such intimate knowledge of anatomy so readily available, it is, as Katherine Park points out, "difficult for twenty-first-century readers to think of this understanding of the body as having had a beginning."

Yet for most of history, the interior structures of the body were relatively unknown, with suppositions made largely on the basis of ancient writings. This despite the fact that no great technological advances were required to uncover the body's mysteries: rather, a change in attitudes toward dissection was necessary. How this occurred, particularly with regard to the study of female reproductive anatomy, is the subject of Secrets of Women: Gender, Generation, and the Origins of Human Dissection.

Park is a Professor of the History of Science at Harvard University, and in Secrets of Women she describes practices of dissection in late medieval and Renaissance Italy as they relate to a variety of cultural factors. Through case examples, and figures drawn from i5th-century paintings and texts, she shows how interest in the manifestation of spiritual phenomena by the body, concerns about inheritance, and the increasing importance of the medical profession all contributed to the growth of knowledge about female anatomy, not only through dissection as taught at medical schools, but through funerary rituals, the acquisition of relics from the bodies of Christian saints, autopsies, and cesarian sections.

Park writes in an authoritative, scholarly fashion, which can be a bit dry at times. More than a third of the total page count is given over to notes and an index, and the level of detail can be such that more general points about the prevailing philosophies and attitudes of the time are overshadowed. Yet while this book does not seem to be intended for the general reader, it should be accessible for most physicians. The cases of the women who were dissected are engaging, even if they are related in a strict academic fashion rather than as creative histories. And there is a certain amount of interesting trivia, such as the fact that women in the I5th century were often served from wooden "childbirth trays" that were painted with the image of a healthy male infant to increase the chances that they would produce a well-formed male heir.

"What does it mean to know our bodies?" asks Park. This book, in attempting to address this question, provokes reflection not only on how medical knowledge has evolved in the past
500 years, but also on how our current knowledge of anatomy influences our understanding of ourselves.

Lara Hazelton MD

Psychiatrist

Halifax, NS

\section{It's elementary medicine,}

\section{my dear Watson}

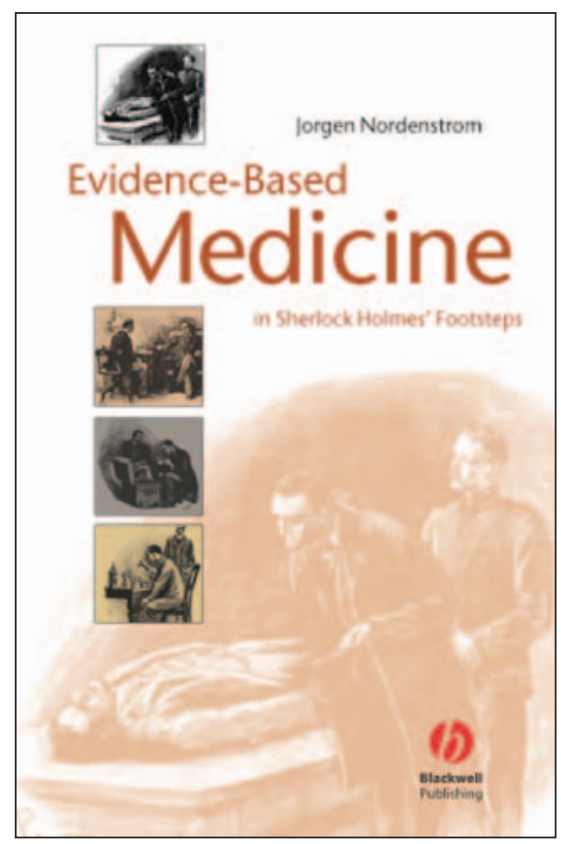

Evidence-Based Medicine in Sherlock Holmes' Footsteps

Jorgen Nordenstorm

Blackwell Publishing

91 pp \$22.95 ISBN: 978-1-4051-5713-1

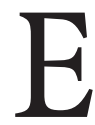

vidence-Based Medicine in Sherlock Holmes' Footsteps is useful; not particularly innovative, nothing truly groundbreaking, but useful to students and users of evidencebased medicine. The author sets out to write a short, concise book about the evidence-based medicine process and does succeed in doing just that.

The process is described as having 4 ì steps; each of the book's 4 chapters describes a step. The author points out that $\frac{5}{N}$ the steps can be remembered by the Ôn mnemonic FIRE. Step I: Formulate the question; Step 2: Information search; Step 3: Review the information (critical 